\title{
Conidiation in Neurospora crassa: vegetative reproduction by a model fungus
}

\author{
Carmen Ruger-Herreros $^{1,2}$ (D) Luis M. Corrochano $^{3}$ \\ Received: 12 March 2019 / Revised: 14 May 2019 / Accepted: 20 May 2019 \\ (C) Springer Nature Switzerland AG 2019
}

\begin{abstract}
Asexual development, conidiation, in the filamentous fungus Neurospora crassa is a simple developmental process that starts with the growth of aerial hyphae. Then, the formation of constrictions and subsequent maturation gives rise to the mature conidia that are easily dispersed by air currents. Conidiation is regulated by environmental factors such as light, aeration and nutrient limitation, and by the circadian clock. Different regulatory proteins acting at different stages of conidiation have been described. The role of transcription factors such as FL, and components of signal transduction pathways such as the cAMP phosphodiesterase ACON-2 suggest a complex interplay between differential transcription and signal transduction pathways. Comparisons between the molecular basis of conidiation in N. crassa and other filamentous fungi will help to identify common regulatory elements.
\end{abstract}

Keywords Asexual development $\cdot$ Conidiation $\cdot$ Neurospora $\cdot$ Sporulation

\section{Introduction}

Neurospora crassa is an ascomycete heterothallic filamentous fungus that grows as branched multinucleated hyphae with perforated septa. In nature, species of Neurospora have been found in a wide range or areas that include tropical, subtropical and temperate regions, and the fungus is easily detected growing on the surface of fire-scorched vegetation because of its ability to metabolize cellulose and the activation by heat of the sexual spores (ascospores) (Jacobson et al. 2006; Jacobson et al. 2004; Luque et al. 2012; Turner et al. 2001). N. crassa has been used as a model organism for the research on several aspects of eukaryotic biology, including the mechanism of recombination, genome defence by RNAi, circadian clock regulation and light sensing (Davis and Perkins 2002;

Carmen Ruger-Herreros

c.ruger-herreros@zmbh.uni-heidelberg.de

1 Center for Molecular Biology of the University of Heidelberg (ZMBH), (DKFZ-ZMBH Alliance), Im Neuenheimer Feld 282, 69120 Heidelberg, Germany

2 German Cancer Research Center (DKFZ), Im Neuenheimer Feld 280, 69120 Heidelberg, Germany

3 Departamento de Genética, Facultad de Biología, Universidad de Sevilla, Apartado 1095, 41080 Sevilla, Spain
Perkins and Davis 2000; Roche et al. 2014) The life cycle of $N$. crassa includes asexual reproduction and the development of vegetative conidia that are easy to disperse. The developmental processes that lead to conidiation in $N$. crassa are, however, very different from those regulating conidiation in Aspergillus nidulans, despite both being members of the Ascomycota. Here, we review our knowledge of the regulation, the genetics and molecular basis of conidiation in $N$. crassa. We propose that the simplified mode of vegetative reproduction in $N$. crassa and related fungi may help to understand asexual development in other ascomycetes with more complex conidiation pathways.

\section{Morphological events during conidiation in Neurospora crassa}

There are two pathways for asexual reproduction in $N$. crassa: macroconidiation and microconidiation. Macroconidiation (henceforth conidiation) is induced by the transfer from a liquid to an air interface, desiccation and nutrient depletion, and is influenced by several environmental factors such as light and $\mathrm{CO}_{2}$ levels, and by the circadian rhythm (Springer 1993). Conidiation is a very simple developmental process. The induction of conidiation promotes a change in the direction of growth of the vegetative hyphae that grow away from the substrate, and leads to the formation of a mass of aerial 
hyphae. About $4 \mathrm{~h}$ after conidial induction, hyphal growth changes from apical elongation to apical budding leading to the formation of chains of proconidia that are divided by minor constrictions. Budding continues in proconidial chains, and major constrictions appear approximately $8 \mathrm{~h}$ after the induction of conidiation. This results in the separation of each proconidia during their maturation into full conidia (Fig. 1A). Interconidial junctions are cleaved several hours later, but fragile connective threads hold conidia together until they are dispersed by wind currents (Springer 1993; Springer and Yanofsky 1989). The entire process of conidiation takes between 12 and $24 \mathrm{~h}$. However, conidia undergo a biochemical maturation period of several days before they are able of efficient germination (Fig. 1B).

The other asexual reproduction pathway, microconidiation, is often observed in old cultures. Microconidia are uninucleated spores morphologically and developmentally different from macroconidia. It has been shown that mutants affected in macroconidiation are not affected in microconidiation, suggesting that both pathways are independent and should have few common regulatory elements, if any (Maheshwari 1999). Microconidia emerge from a protuberance in the vegetative hyphae which constricts until microconidia are liberated. Externally, microconidia are smaller than conidia and do not contain carotenoids in their cell wall. They are less viable than macroconidia (Springer
1993; Springer et al. 1992; Springer and Yanofsky 1989). In addition, microcycle conidiation has been observed in wild type isolates of $N$. crassa, but the genetics and morphological characterization have been limited (Maheshwari 1991).

\section{The regulation of conidiation}

The process of conidiation is regulated by a number of environmental factors and endogenous signals that should be properly coordinated by the fungus in order to produce conidia when environmental conditions are appropriate for vegetative reproduction. Conidia formation is normally observed when the fungus is exposed to air, but carbon starvation can induce conidiation in submerged mycelia (Madi et al. 1994; Madi et al. 1997). In N. crassa and other fungi, developmental cycles are often initiated by the same environmental stresses that induce the accumulation of high levels of trehalose, including carbon starvation, increased temperature and desiccation ( $\mathrm{Li}$ et al. 1997; Sargent and Kaltenborn 1972; Springer and Yanofsky 1992; Sun et al. 2011). Moreover, the process of development itself is considered to cause physiological stress on organisms. In mature conidia, higher levels of trehalose and stress response proteins may be required for resistance and survival (Häfker et al. 1998; Rensing and Monnerjahn 1998). Thus, trehalose may play a dual role in the cell, functioning as a reserve carbohydrate for future hyphal growth and
Fig. 1 (A) Developmental timeline of conidiation in Neurospora crassa. (B) Different stages of conidial development visualized by scanning electron microscopy $(\mathrm{a}, \mathrm{b})$ and fluorescence microscopy (c, d, e, f): histone H1-GFP for nuclei visualization and calcofluor white for cell wall staining. Arrows indicate major and minor constrictions (b), hyphal septa $(\mathrm{a}, \mathrm{e})$ and interconidial junctions (f)

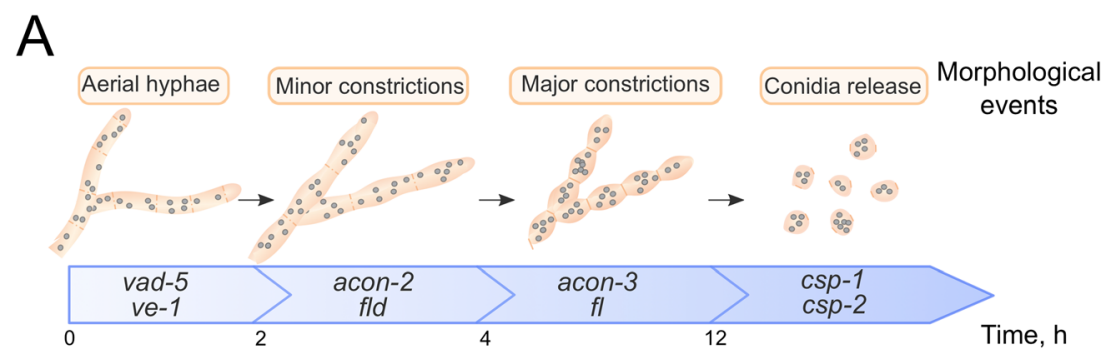

B

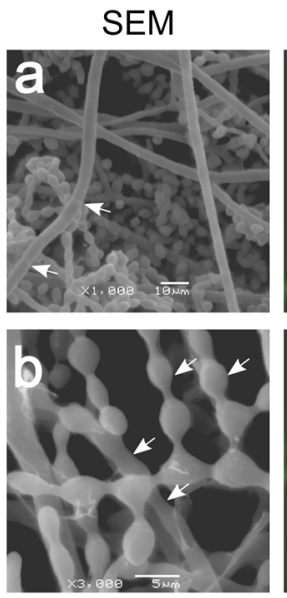

hH1-GFP
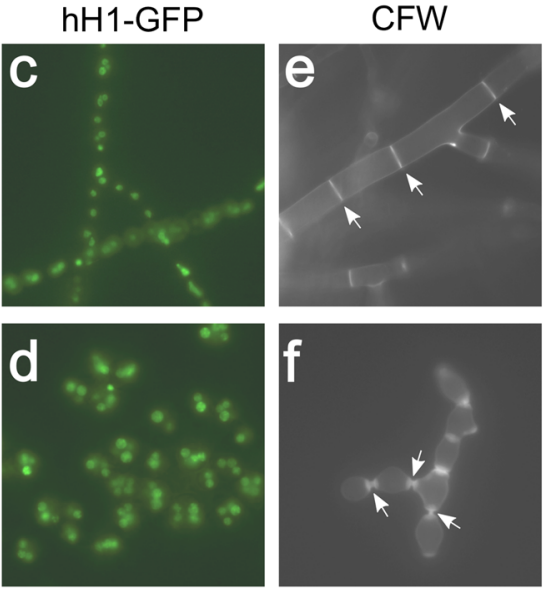
as a stress protectant. The mechanism of induction of conidiation after the transition to an air interphase is not well understood but it has been proposed that the development of conidia helps the fungus to cope with the excess of damaging oxygen radicals (Hansberg et al. 1993; Peraza and Hansberg 2002).

Light regulates conidiation (Springer 1993), and the regulation by light of conidiation requires the activity of proteins WC-1 and WC-2 (Lauter and Russo 1990). WC-1 contains a zinc finger, a chromophore-binding domain (LOV) and PAS domains for protein-protein interactions (Ballario et al. 1996; Crosthwaite et al. 1997). The chromophore-binding domain binds the flavin FAD, allowing WC-1 to act as a blue-light photoreceptor (Froehlich et al. 2002; He et al. 2002). The protein WC-2 contains a zinc finger and a PAS domain, and interacts with WC-1 (Linden and Macino 1997) to form a White Collar Complex (WCC). This complex, upon light exposure, binds transiently to the promoters of light-inducible genes to activate their transcription (Belden et al. 2007; Froehlich et al. 2002; He and Liu 2005; Smith et al. 2010), including the promoter of $f l(f l u f f y$ ), a gene that encodes a key regulator of conidiation. Conidiation increases in $N$. crassa cultures exposed to light suggesting that light may activate the transcription of key regulatory genes which indeed accumulate after light exposure as it has been shown for $f l$ or $c s p-1$ among others (Belden et al. 2007; Chen et al. 2009; Olmedo et al. 2010a; Olmedo et al. 2010b).

Conidiation is regulated by the endogenous circadian clock resulting in bands of conidia every $22.5 \mathrm{~h}$ of growth in the dark (Dunlap and Loros 2017). The mechanism by which the clock regulates conidiation has been characterized in detail and is based on a negative feedback loop in which the positive element is the WCC which activates transcription of frq. FRQ is the negative element of the clock and together with its partners the RNA helicase FRH and the casein kinase-1 (CK-1) blocks its own transcription as well as the transcription of the other WCC-regulated genes (Crosthwaite et al. 1997; Dunlap and Loros 2004; Heintzen and Liu 2007). The oscillatory amount of FRQ during the circadian cycle promotes changes in the abundance, phosphorylation and activity of the WCC during growth in the dark (Brunner and Schafmeier 2006; Dunlap 2006; Dunlap and Loros 2006).

\section{Genetics of conidiation: regulatory genes and proteins}

Genetics has helped to identify some of the key elements that regulate conidiation in $N$. crassa. Several genes required for conidiation have been described and their genetic interactions have been established. Strains with mutations in aconidiate-2 (acon-2) or fluffyoid (fld) are blocked in the transition from filamentous to budding growth. Mutations in aconidiate-3 (acon-3) or fluffy (fl) allow the production of minor constrictions, but development is blocked and few major constrictions between proconidia are detected. Mutations in two conidial separation genes (csp-1 and $c s p$-2) prevent the separation of the cross walls in matured conidia to release free conidia (Springer 1993). Of these genes, attention has focused on the products of genes $f l$ (NCU08726), $c s p-1$ (NCU02713) and $c s p-2$ (NCU06095) that are transcription factors that should act by regulating transcription of genes that participate in the development of conidia. These genes are all light-inducible providing a connection between light regulation and conidiation (Bailey and Ebbole 1998; Chen et al. 2009; Lambreghts et al. 2009; Paré et al. 2012; Smith et al. 2010).

The $f l$ gene has been characterized in detail. The FL protein is a 792-amino acid polypeptide containing a $\mathrm{Zn}_{2} \mathrm{Cys}_{6}$ binuclear zinc cluster domain belonging to the Gal4p family (Bailey and Ebbole 1998). Mutations in $f l$ block conidiation at the formation of minor constrictions, few hours after the induction of conidiation (Springer and Yanofsky 1989). $f l$ mRNA accumulates in aerial hyphae where conidiationspecific genes are expressed suggesting an important role for FL in the expression of those genes (Bailey-Shrode and Ebbole 2004). However, it has been also found that $f l$ mRNA accumulates shortly after induction of conidiation suggesting an additional role for FL in the formation of aerial hyphae (Correa and Bell-Pedersen 2002). The importance of FL as one of the major regulators of conidiation in N. crassa relies on the observation of conidial development when $f l$ is overexpressed in submerged vegetative hyphae (BaileyShrode and Ebbole 2004). The overexpression of $f l$ in vegetative hyphae leads to the expression of eas (Bailey-Shrode and Ebbole 2004), the gene for the hydrophobin rodlet protein located on the surface of matured conidia (Bell-Pedersen et al. 1992; Lauter et al. 1992). This observation supports the described binding of FL to the eas promoter (Rerngsamran et al. 2005). Other regulatory genes have been found to be upregulated when $f l$ is overexpressed in vegetative mycelia, including the conidiation-specific genes con- 6 and con-10 (Rerngsamran et al. 2005) supporting the proposal of FL as a conidiation-specific transcription factor. It has been described that the aconidial phenotype of a $f l$ mutant can be partially suppressed by mutation in the gene $v i b-1$, a transcription factor that is involved in the regulation of heterokaryon incompatibility. This would suggest that FL may regulate conidiation through the repression of VIB-1 (Xiang and Glass 2002). The $f l$ gene is directly activated by light through the binding of the WCC to a light regulatory element on its promoter located at position - 640 from initiator ATG (Olmedo et al. 2010a). $f l$ mRNA accumulates rhythmically in an ACON-2-dependent manner (Correa and BellPedersen 2002), supporting the proposal that the rhythmic production of conidial bands requires the rhythmic accumulation of $f l$ mRNA. 
Other conidiation mutants have been isolated and characterized. ACON-2 is a cAMP phosphodiesterase, but its role in the regulation of conidiation remains to be investigated in detail (Greenwald et al. 2010), and FLD has been proposed to be a transcription factor (Carrillo et al. 2017; McCluskey et al. 2011). ACON-3 is a protein without any identified domain and is the homologue of MedA, a protein that participates in the regulation of conidiation of Aspergillus nidulans (Chung et al. 2011). It is interesting to note the abundance of transcription factor mutants that are blocked in conidiation. CSP-1 is a light-inducible zinc finger transcription factor (Lambreghts et al. 2009; Smith et al. 2010) and CSP-2 was identified as a light-regulated grainy head-like transcription factor (Colot et al. 2006; Paré et al. 2012). CSP-2 is involved in the development and remodelling of the cell wall and plays a role in the activation of genes related with defence and virulence (Paré et al. 2012). A third transcription factor, FLB-3, has been recently characterized. It is the $N$. crassa homologue of FlbC, a transcription factor that participates in the regulation of $A$. nidulans conidiation. The $f l b-3$ mutant is blocked in conidiation, shows altered sexual development and is unable to complete the sexual cycle (Boni et al. 2018). These results suggest that FLB-3 plays a key role in the transcriptional coordination between asexual and sexual reproduction.

\section{Transcriptional regulation during conidiation}

The discovery that several transcription factors regulate conidiation suggested a key role in transcriptional regulation during conidiation. In addition, several genes have been found to be highly expressed during conidiation (Roberts et al. 1988) although their mutants do not have a clear developmental phenotype. The con genes of $N$. crassa are preferentially expressed during conidiation but some of them are also induced by light in vegetative mycelia in a WC-dependent manner (Corrochano et al. 1995; Lauter and Russo 1991; Madi et al. 1994). The genes con-10 and con-6 contain several regulatory elements in their promoters that are responsible for their transcriptional regulation by development, light and the circadian clock (Corrochano et al. 1995; Lee and Ebbole 1998; Olmedo et al. 2010b). Similar complex regulation has been observed for genes con-5 and con-13, since they are regulated by light and conidiation although their promoters have not been extensively characterized.

The availability of the $N$. crassa genome sequence made possible the creation of a gene knockout mutant collection for almost all the genes identified in the genome (Colot et al. 2006; Dunlap et al. 2007). The viable knockout mutants have been analysed and their developmental phenotypes have been characterized (Borkovich et al. 2004; Carrillo et al. 2017; Colot et al. 2006). Several strains bearing mutations in genes coding for transcription factors have shown defects in different stages of the $N$. crassa life cycle. Most of them were found to have impaired asexual sporulation although the correlation between the phenotypes and gene expression during conidiation has not been stablished for most genes yet (Carrillo et al. 2017).

In a few cases, the role of transcriptional regulators on conidiation has been investigated. Mutations in the Gal4like transcription factor VAD-5 or the velvet protein VE1 reduce the growth of aerial hyphae (Bayram et al. 2008; Sun et al. 2012). The gene $c h c-1$ encodes a protein with a helix-loop-helix binding domain and the mutant shows enhanced conidiation, in particular under high $\mathrm{CO}_{2}$ (Sun et al. 2011).

\section{Signal transduction pathways that regulate conidiation}

The key role of the cAMP phosphodiesterase ACON-2 in conidiation indicated that other signal transduction pathways participated in the regulation of conidiation in addition to the transcriptional regulation of conidiation genes.

Conidiation in $N$. crassa is also regulated by signalling pathways based on heterotrimeric $\mathrm{G}$ proteins and $\mathrm{G}$ proteincoupled receptors (GPCR). G proteins play key roles as signalling proteins in eukaryotes where they form heterotrimers composed of $\alpha, \beta$ and $\gamma$ subunits which are associated with the plasma membrane (Neves et al. 2002; Won et al. 2012). The G $\alpha$ subunit binds GTP and GDP and hydrolyses GTP to GDP, and the $G \beta$ and $G \gamma$ subunits form a dimer. In the inactive state, the G $\alpha$ subunit binds GDP and the three subunits are present in a complex in association with a GPCR. Ligand binding to the GPCR leads to exchange of GTP for GDP on the $G \alpha$ protein and dissociation of the $G \alpha$ and $G \beta \gamma$ dimer. Both the G $\alpha$-GTP and G $\beta \gamma$ moieties regulate downstream effector proteins in various systems, including ion channels, adenylyl-cyclases, phosphodiesterases and phospholipases. GTP hydrolysis on the G $\alpha$ subunit allows the GDP-bound $\mathrm{G} \alpha$ to reassociate with the G $\beta \gamma$ dimer and the GPCR at the membrane, ready to reinitiate the signalling cycle ( $\mathrm{Li}$ et al. 2007).

Neurospora has three G $\alpha$ subunits (GNA 1-3), one G $\beta$ protein (GNB-1), one $\mathrm{G} \gamma$ protein (GNG-1) and several predicted GPCRs (Li et al. 2007). GNA-1 was the first identified $\mathrm{G}$ protein subunit in filamentous fungi, and participates together with the GPCR GPR-4 and the protein kinase A (PKA) in the regulation of carbon source-dependent apical growth and asexual development (Ivey et al. 1996; Ivey et al. 2002; Ivey et al. 1999; Li and Borkovich 2006; Turner and Borkovich 1993). GNA-3 regulates conidiation via modulating a cAMP-dependent pathway and acts as a negative regulator of conidiation (Kays and Borkovich 2004; Kays et al. 2000). The GNB-1 (G $\beta) / G N G-1(G \gamma)$ dimer is required for the stability of $\mathrm{G} \alpha$ proteins and acts as a repressor of 
conidiation (Krystofova and Borkovich 2005; Yang et al. 2002). Recent studies have demonstrated that RIC-8 (resistant to inhibitors of cholinesterase) positively regulates $\mathrm{G} \alpha$ subunits, GNA-1 and GNA-3, and deletion of ric- 8 results in defects in growth and asexual development. Mutations that activate the GNA-1 and GNA-3 proteins in the $\Delta r i c-8$ background partially suppress $\Delta r i c-8$ phenotypes. RIC- 8 interacts with GNA-1 and GNA-3 in the yeast two-hybrid assays and acts as a GEF (guanine nucleotide exchange factor) for GNA1 and GNA-3 in vitro (Wright et al. 2011). The phenotypes of mutants in 36 GPCRs have been analysed. Mutations in 14 GPCR genes lead to alterations in conidiation, specifically in the formation of aerial hyphae. About half of the mutants showed a reduction, and half of the mutant had an increase in the amount of aerial hyphae. Several mutants had pleiotropic effects on development suggesting cross regulations between hyphal growth, sexual and asexual development in N. crassa (Cabrera et al. 2015).

Mutants in components of other signal transduction pathways show alterations in conidiation. Mutants in genes coding for calcium signalling components suggest a role for calcium signalling in conidiation (Barman and Tamuli 2017). The GTP-binding cytoskeletal proteins septins participate in cell polarity and the strains with deletions in septin genes show alterations in conidiation, among other developmental phenotypes (Berepiki and Read 2013).

In addition, kinases participate in the regulation of conidiation. The NDR kinase COT-1 regulates hyphal branching and interacts with several proteins that modulate its regulatory activities. The interacting proteins include MOB2A/B, the arginine methyltransferase SKB1 and the regulatory subunits of the protein phosphatase 2A. Mutations in these proteins lead to changes in the regulation of COT-1 activity and alterations in conidiation, suggesting that they play a regulatory role in this developmental process (Dvash et al. 2010; Feldman et al. 2013; Shomin-Levi and Yarden 2017; Ziv et al. 2013). The mutant in the second NDR kinase, DBF-2, shows alterations in the growth of aerial hyphae and conidiation (Dvash et al. 2010), and a similar phenotype is observed in the mutant in the putative histidine kinase DCC1 (Barba-Ostria et al. 2011).

\section{Comparison of conidiation in N. crassa with the asexual program of other ascomycetes}

The widespread occurrence of conidiation in ascomycetes highlights the importance of this process during the evolution of this group of fungi (Berbee and Taylor 2001). N. crassa and A. nidulans diverged more than 300 million years ago (Taylor and Berbee 2006; Taylor and Ellison 2010). Conidiation in A. nidulans has been investigated in detail and several mutants affected on conidiation have been characterized (Park and Yu 2012). These mutants provide the tools to address questions about the evolution of conidiation. Morphologically, asexual development in A. nidulans is significantly different from that in $N$. crassa. In A. nidulans, conidiation begins with the formation of a foot cell and is followed by successive emergence of the stalk, vesicle, metulae, phialides and finally aerial spores or conidia (Park and Yu 2012). The master regulator of conidiation in A. nidulans is encoded by the gen $\mathrm{brlA}$ (bristle). Although it has no sequence similarity with $f l$, the activation of brlA transcription is sufficient to induce conidiation, and in a similar manner to $f l, b r l A$ is activated by light in a WC-dependent manner (Mooney and Yager 1990; Ruger-Herreros et al. 2011). BrlA activates transcription of another regulatory gene, $a b a A$ (abacus). Unlike brlA, overexpression of $a b a A$ does not induce conidiation but does cause an arrest of vegetative growth and induction of genes normally observed during conidiation (Adams et al. 1990; Adams et al. 1998). There are many other genes acting upstream of BrlA and whose mutation gives rise to aconidial phenotypes. Most of these genes are conserved in the Aspergilli (Ojeda-Lopez et al. 2018). Some of these genes are also found in the N. crassa genome (Fig. 2) and have been found to complement the defect on sporulation on the corresponding mutants in A. nidulans (Table 1) (Chung et al. 2011; Shen et al. 1998). Despite the presence of several homologous genes between A. nidulans and $N$. crassa, their conidiation pathways differ in both their regulation and morphology, highlighting the simplicity of the conidiation program in $N$. crassa (Fig. 2).

\section{Conclusion}

Conidiation in $N$. crassa has a complex regulation but is a simple developmental process when compared with vegetative reproduction in other filamentous fungi. The isolation of aconidial mutants and the identification of the genes involved showed that differential transcription and signal transduction pathways have key roles in conidiation. The role of environmental regulation in conidiation is less understood. The role of light on the regulation of conidiation by controlling transcription of $f l$ and other key regulatory genes has been proposed, but the connection between nutrient sensing and conidiation, and how the transition from a liquid to an air interphase activates conidiation remain to be investigated in detail. It is possible that some of these environmental signals are sensed by any of the GPCRs that have been described in $N$. crassa. The $N$. crassa genome sequence and the collection of single mutants with deletions in most of the genes in the genome have provided a large collection of mutants with altered conidiation. The large number of conidiation mutants suggests that altering conidiation is not very difficult, but identifying key regulators, like FL or ACON-2, required genetic screens and 


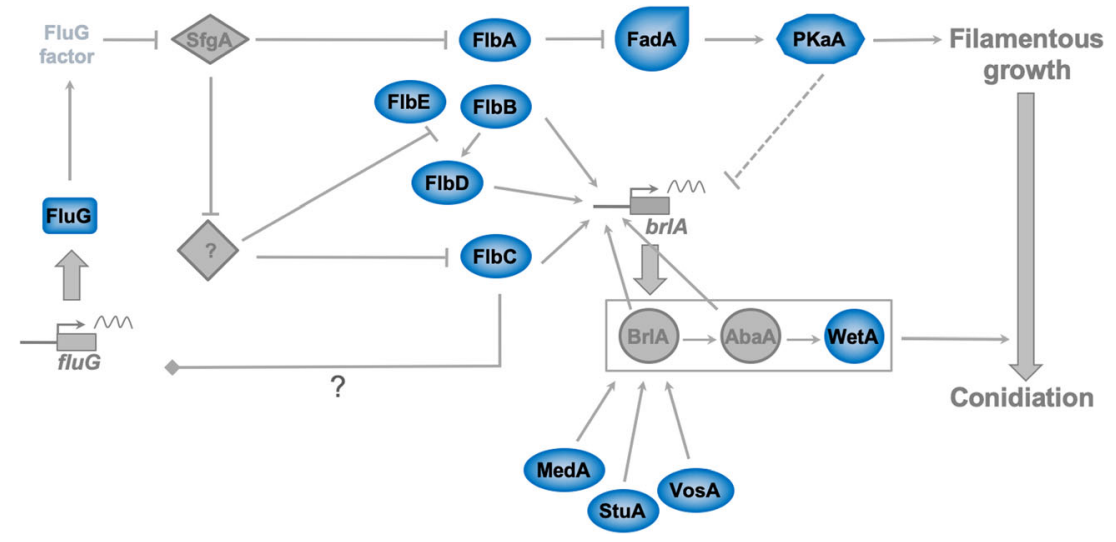

Fig. 2 Comparison between the regulatory genes controlling conidiation in A. nidulans (in grey) vs. N. crassa (in blue). Conidiation in A. nidulans is controlled by the master regulator $b r l A$ which is necessary and sufficient to induce asexual development. Different pathways lead to the transcriptional activation of $\mathrm{brlA}$ : a protein kinase A-dependent cascade which promotes filamentous growth is blocked by the action of FluG

strong mutant phenotypes, not a reduction or increase in conidiation. Future work should focus on identifying new key regulators of conidiation perhaps by looking for conditional aconidial mutants.

Table 1 Homologous genes between A. nidulans and N. crassa and the corresponding phenotype of the knockout mutants

\begin{tabular}{lll}
\hline $\begin{array}{l}\text { Aspergillus } \\
\text { nidulans }\end{array}$ & Neurospora crassa & $\begin{array}{l}\text { Phenotype of the N.crassa } \\
\text { mutant }\end{array}$ \\
\hline sfgA & - & - \\
$f l u G$ & NCU04264 & Wild type \\
$f l b A$ & NCU08319 & Wild type \\
$f l b B$ & NCU07379, tcf-5 & Wild type \\
$f l b C$ & NCU03043, flb-3 & Aconidial \\
$f l b D$ & NCU01312, rca-1 & Wild type \\
$f l b E$ & NCU05255 & Unknown \\
$f a d A$ & NCU06493, gna-1 & Wild type \\
pkaA & NCU06240, pkac-1 & Pleiotropic \\
stuA & NCU01414, asm-1 & Short aerial hyphae \\
vosA & NCU05964, vos-1 & Reduced conidiation \\
$m e d A$ & NCU07617, & Aconidial \\
brlA & acon-3 & \\
abaA & - & - \\
wetA & - & - \\
- & NCU01033 & Wild type \\
- & NCU8726, fl & Aconidial \\
AN1251 & NCU9739, fld & Aconidial \\
AN4878 & NCU2713, csp-1 & Conidial separation defective \\
pdeB & NCU06095, csp-2 & Conidial separation defective \\
& NCU00478, & Aconidial \\
\hline & acon-2 & \\
\hline
\end{tabular}

factor. At the same time, several fluffy genes ( $f l b$ genes) directly activate transcription of brlA. In this scenario, many of the genes important for conidiation in A. nidulans are also present in $N$. crassa genome although the morphological and regulatory processes in both fungi substantially differ.

The comparison of the conidiation pathways in $N$. crassa and A. nidulans shows a few common features like the regulation by light of key transcriptional regulators, and the key role of transcriptional regulation, but many differences like those in morphology and the use of specific proteins in each pathway. It seems that there is not a basic conidiation pathway shared by all ascomycetes but different developmental solutions based on differential transcription and common signal transduction pathways to the problem of how to develop conidia. However, we expect that further characterization of conidiation in $N$. crassa and comparison with other filamentous fungi will help to identify common elements in the regulation of fungal development.

Acknowledgements Research in the laboratory of LMC is supported by the Spanish Ministry of Science, Innovation and Universities (BIO201567148-R) and European Funds (European Regional Development Fund, ERDF).

\section{Compliance with ethical standards}

Conflict of interest The authors declare that they have no conflict of interest.

\section{References}

Adams TH, Deising H, Timberlake WE (1990) brlA requires both zinc fingers to induce development. Mol Cell Biol 10:18151817

Adams TH, Wieser JK, Yu JH (1998) Asexual sporulation in Aspergillus nidulans. Microbiol Mol Biol Rev 62:35-54

Bailey LA, Ebbole DJ (1998) The fluffy gene of Neurospora crassa encodes a Gal4p-type C6 zinc cluster protein required for conidial development. Genetics 148:1813-1820 
Bailey-Shrode L, Ebbole DJ (2004) The fluffy gene of Neurospora crassa is necessary and sufficient to induce conidiophore development. Genetics 166:1741-1749

Ballario P, Vittorioso P, Magrelli A, Talora C, Cabibbo A, Macino G (1996) White collar-1, a central regulator of blue light responses in Neurospora, is a zinc finger protein. EMBO J 15:1650-1657

Barba-Ostria C, Lledías F, Georgellis D (2011) The Neurospora crassa DCC-1 protein, a putative histidine kinase, is required for normal sexual and asexual development and carotenogenesis. Eukaryot Cell 10:1733-1739. https://doi.org/10.1128/EC.05223-11

Barman A, Tamuli R (2017) The pleiotropic vegetative and sexual development phenotypes of Neurospora crassa arise from double mutants of the calcium signaling genes plc-1, splA2, and cpe-1. Curr Genet 63:861-875. https://doi.org/10.1007/s00294-017-0682-y

Bayram O, Krappmann S, Seiler S, Vogt N, Braus GH (2008) Neurospora crassa ve-1 affects asexual conidiation. Fungal Genet Biol 45:127138. https://doi.org/10.1016/j.fgb.2007.06.001

Belden WJ, Larrondo LF, Froehlich AC, Shi M, Chen C-H, Loros JJ, Dunlap JC (2007) The band mutation in Neurospora crassa is a dominant allele of RAS-1 implicating RAS signaling in circadian output. Genes Dev 21:1494-1505. https://doi.org/10.1101/gad. 1551707

Bell-Pedersen D, Dunlap JC, Loros JJ (1992) The Neurospora circadian clock-controlled gene, ccg-2, is allelic to eas and encodes a fungal hydrophobin required for formation of the conidial rodlet layer. Genes Dev 6:2382-2394

Berbee ML, Taylor JW (2001) Fungal molecular evolution: gene trees and geologic time. In: McLaughlin DJ, McLaughlin EG, Lemke PA (eds) Systematics and evolution. Springer, Berlin Heidelberg, pp 229-245. https://doi.org/10.1007/978-3-662-10189-6_10

Berepiki A, Read ND (2013) Septins are important for cell polarity, septation and asexual spore formation in Neurospora crassa and show different patterns of localisation at germ tube tips. PLoS One 8:e63843. https://doi.org/10.1371/journal.pone.0063843

Boni AC et al (2018) Neurospora crassa developmental control mediated by the FLB-3 transcription factor. Fungal Biol. 122:570-582. https://doi.org/10.1016/j.funbio.2018.01.004

Borkovich KA et al (2004) Lessons from the genome sequence of Neurospora crassa: tracing the path from genomic blueprint to multicellular organism. Microbiol Mol Biol Rev 68:1-108

Brunner M, Schafmeier T (2006) Transcriptional and post-transcriptional regulation of the circadian clock of cyanobacteria and Neurospora. Genes Dev 20:1061-1074. https://doi.org/10.1101/gad.1410406

Cabrera IE et al (2015) Global analysis of predicted G protein-coupled receptor genes in the filamentous fungus, Neurospora crassa. G3 (Bethesda) 5:2729-2743. https://doi.org/10.1534/g3.115.020974

Carrillo AJ et al (2017) Functional profiling of transcription factor genes in Neurospora crassa. G3 (Bethesda, Md) 7:2945-2956. https://doi. org/10.1534/g3.117.043331

Chen C-H, Ringelberg CS, Gross RH, Dunlap JC, Loros JJ (2009) Genome-wide analysis of light-inducible responses reveals hierarchical light signalling in Neurospora. EMBO J 28:1029-1042. https://doi.org/10.1038/emboj.2009.54

Chung D-W, Greenwald C, Upadhyay S, Ding S, Wilkinson HH, Ebbole DJ, Shaw BD (2011) Acon-3, the Neurospora crassa ortholog of the developmental modifier, medA, complements the conidiation defect of the Aspergillus nidulans mutant. Fungal Genet Biol 48:370-376. https://doi.org/10.1016/j.fgb.2010.12.008

Colot HV et al (2006) A high-throughput gene knockout procedure for Neurospora reveals functions for multiple transcription factors. Proc Natl Acad Sci USA 103:10352-10357. https://doi.org/10.1073/ pnas.0601456103

Correa A, Bell-Pedersen D (2002) Distinct signaling pathways from the circadian clock participate in regulation of rhythmic conidiospore development in Neurospora crassa. Eukaryot Cell 1:273-280
Corrochano LM, Lauter FR, Ebbole DJ, Yanofsky C (1995) Light and developmental regulation of the gene con-10 of Neurospora crassa. Dev Biol 167:190-200. https://doi.org/10.1006/dbio.1995.1016

Crosthwaite SK, Dunlap JC, Loros JJ (1997) Neurospora wc-1 and wc-2: transcription, photoresponses, and the origins of circadian rhythmicity. Science 276:763-769

Davis RH, Perkins DD (2002) Timeline: Neurospora: a model of model microbes. Nat Rev Genet 3:397-403. https://doi.org/10.1038/ $\operatorname{nrg} 797$

Dunlap JC (2006) Proteins in the Neurospora circadian clockworks. J Biol Chem 281:28489-28493. https://doi.org/10.1074/jbc. R600018200

Dunlap JC, Loros JJ (2004) The neurospora circadian system. J Biol Rhythm 19:414-424. https://doi.org/10.1177/0748730404269116

Dunlap JC, Loros JJ (2006) How fungi keep time: circadian system in Neurospora and other fungi. Curr Opin Microbiol 9:579-587. https://doi.org/10.1016/j.mib.2006.10.008

Dunlap JC, Loros JJ (2017) Making time: conservation of biological clocks from fungi to animals. Microbiol Spectr. $5 \mathrm{https}$ :/doi.org/ 10.1128/microbiolspec.FUNK-0039-2016

Dunlap JC et al (2007) A circadian clock in Neurospora: how genes and proteins cooperate to produce a sustained, entrainable, and compensated biological oscillator with a period of about a day. Cold Spring Harb Symp Quant Biol 72:57-68. https://doi.org/10.1101/sqb.2007. 72.072

Dvash E, Kra-Oz G, Ziv C, Carmeli S, Yarden O (2010) The NDR kinase DBF-2 is involved in regulation of mitosis, conidial development, and glycogen metabolism in Neurospora crassa. Eukaryot Cell 9: 502-513. https://doi.org/10.1128/EC.00230-09

Feldman D, Ziv C, Gorovits R, Efrat M, Yarden O (2013) Neurospora crassa protein arginine methyl transferases are involved in growth and development and interact with the NDR kinase COT1. PLoS One 8:e80756. https://doi.org/10.1371/journal.pone.0080756

Froehlich AC, Liu Y, Loros JJ, Dunlap JC (2002) White Collar-1, a circadian blue light photoreceptor, binding to the frequency promoter. Science (New York, NY) 297:815-819. https://doi.org/10.1126/ science. 1073681

Greenwald CJ, Kasuga T, Glass NL, Shaw BD, Ebbole DJ, Wilkinson $\mathrm{HH}$ (2010) Temporal and spatial regulation of gene expression during asexual development of Neurospora crassa. Genetics 186:12171230. https://doi.org/10.1534/genetics. 110.121780

Häfker T, Techel D, Steier G, Rensing L (1998) Differential expression of glucose-regulated (grp78) and heat-shock-inducible (hsp70) genes during asexual development of Neurospora crassa. Microbiology (Reading, England) 144(Pt 1):37-43

Hansberg W, de Groot H, Sies H (1993) Reactive oxygen species associated with cell differentiation in Neurospora crassa. Free Radic Biol Med 14:287-293

He Q, Liu Y (2005) Molecular mechanism of light responses in Neurospora: from light-induced transcription to photoadaptation. Genes Dev 19:2888-2899. https://doi.org/10.1101/gad.1369605

He Q, Cheng P, Yang Y, Wang L, Gardner KH, Liu Y (2002) White collar-1, a DNA binding transcription factor and a light sensor. Science 297:840-843. https://doi.org/10.1126/science.1072795

Heintzen C, Liu Y (2007) The Neurospora crassa circadian clock. Adv Genet 58:25-66. https://doi.org/10.1016/S0065-2660(06)58002-2

Ivey FD, Hodge PN, Turner GE, Borkovich KA (1996) The G alpha i homologue gna-1 controls multiple differentiation pathways in Neurospora crassa. Mol Biol Cell 7:1283-1297

Ivey FD, Yang Q, Borkovich KA (1999) Positive regulation of adenylyl cyclase activity by a galphai homolog in Neurospora crassa. Fungal Genet Biol 26:48-61. https://doi.org/10.1006/fgbi.1998.1101

Ivey FD, Kays AM, Borkovich KA (2002) Shared and independent roles for a Galpha(i) protein and adenylyl cyclase in regulating development and stress responses in Neurospora crassa. Eukaryot Cell 1: 634-642. https://doi.org/10.1128/EC.1.4.634 
Jacobson DJ et al (2004) Neurospora in temperate forests of western North America. Mycologia 96:66-74

Jacobson DJ et al (2006) New findings of Neurospora in Europe and comparisons of diversity in temperate climates on continental scales. Mycologia 98:550-559

Kays AM, Borkovich KA (2004) Severe impairment of growth and differentiation in a Neurospora crassa mutant lacking all heterotrimeric G alpha proteins. Genetics 166:1229-1240

Kays AM, Rowley PS, Baasiri RA, Borkovich KA (2000) Regulation of conidiation and adenylyl cyclase levels by the Galpha protein GNA3 in Neurospora crassa. Mol Cell Biol 20:7693-7705

Krystofova S, Borkovich KA (2005) The heterotrimeric G-protein subunits GNG-1 and GNB-1 form a Gbetagamma dimer required for normal female fertility, asexual development, and galpha protein levels in Neurospora crassa. Eukaryot Cell 4:365-378. https://doi. org/10.1128/EC.4.2.365-378.2005

Lambreghts $\mathrm{R}$ et al (2009) A high-density single nucleotide polymorphism map for Neurospora crassa. Genetics 181:767-781. https:// doi.org/10.1534/genetics.108.089292

Lauter FR, Russo VE (1990) Light-induced dephosphorylation of a $33 \mathrm{kDa}$ protein in the wild-type strain of Neurospora crassa: the regulatory mutants wc-1 and wc-2 are abnormal. J Photochem Photobiol B 5:95-103

Lauter FR, Russo VE (1991) Blue light induction of conidiation-specific genes in Neurospora crassa. Nucleic Acids Res 19:6883-6886

Lauter FR, Russo VE, Yanofsky C (1992) Developmental and light regulation of eas, the structural gene for the rodlet protein of Neurospora. Genes Dev 6:2373-2381

Lee K, Ebbole DJ (1998) Analysis of two transcription activation elements in the promoter of the developmentally regulated con-10 gene of Neurospora crassa. Fungal Genet Biol 23:259-268. https://doi. org/10.1006/fgbi.1998.1043

Li L, Borkovich KA (2006) GPR-4 is a predicted G-protein-coupled receptor required for carbon source-dependent asexual growth and development in Neurospora crassa. Eukaryot Cell 5:1287-1300. https://doi.org/10.1128/EC.00109-06

Li C, Sachs MS, Schmidhauser TJ (1997) Developmental and photoregulation of three Neurospora crassa carotenogenic genes during conidiation induced by desiccation. Fungal Genet Biol 21: 101-108

Li L, Wright SJ, Krystofova S, Park G, Borkovich KA (2007) Heterotrimeric $\mathrm{G}$ protein signaling in filamentous fungi. Annu Rev Microbiol 61:423-452. https://doi.org/10.1146/annurev.micro.61. 080706.093432

Linden H, Macino G (1997) White collar 2, a partner in blue-light signal transduction, controlling expression of light-regulated genes in Neurospora crassa. EMBO J 16:98-109. https://oi.org/10.1093/ emboj/16.1.98

Luque EM et al. (2012) A relationship between carotenoid accumulation and the distribution of species of the fungus neurospora in spain PLoS ONE 7 doi:https://doi.org/10.1371/journal.pone.0033658

Madi L, Ebbole DJ, White BT, Yanofsky C (1994) Mutants of Neurospora crassa that alter gene expression and conidia development. Proc Natl Acad Sci USA 91:6226-6230

Madi L, Mcbride SA, Bailey LA, Ebbole DJ (1997) Gene involved i n glucose transport and conidiation i $n$

Maheshwari R (1991) Microcycle conidiation and its genetic-basis in Neurospora-Crassa. J Gen Microbiol 137:2103-2115. https://doi. org/10.1099/00221287-137-9-2103

Maheshwari R (1999) Microconidia ofNeurospora crassa fungal genetics and biology 26:1-18 doi:https://doi.org/10.1006/FGBI.1998.1103

McCluskey K, Wiest AE, Grigoriev IV, Lipzen A, Martin J, Schackwitz W, Baker SE (2011) Rediscovery by whole genome sequencing: classical mutations and genome polymorphisms in Neurospora crassa. G3 (Bethesda) 1:303-316. https://doi.org/10.1534/g3.111. 000307
Mooney JL, Yager LN (1990) Light is required for conidiation in Aspergillus nidulans. Genes Dev 4:1473-1482

Neves SR, Ram PT, Iyengar R (2002) G protein pathways. Science 296: 1636-1639. https://doi.org/10.1126/science. 1071550

Ojeda-Lopez M et al (2018) Evolution of asexual and sexual reproduction in the aspergilli. Stud Mycol 91:37-59. https://doi.org/10.1016/j. simyco.2018.10.002

Olmedo M, Ruger-Herreros C, Corrochano LM (2010a) Regulation by blue light of the fluffy gene encoding a major regulator of conidiation in Neurospora crassa Genetics 184 doi:https://doi.org/ 10.1534/genetics.109.109975

Olmedo M, Ruger-Herreros C, Luque EM, Corrochano LM (2010b) A complex photoreceptor system mediates the regulation by light of the conidiation genes con-10 and con- 6 in Neurospora crassa Fungal Genet Biol 47 doi:https://doi.org/10.1016/j.fgb.2009.11.004

Paré A, Kim M, Juarez MT, Brody S, McGinnis W (2012) The functions of grainy head-like proteins in animals and fungi and the evolution of apical extracellular barriers. PLoS One 7:e36254. https://doi.org/ 10.1371/journal.pone.0036254

Park H-S, Yu J-H (2012) Genetic control of asexual sporulation in filamentous fungi Curr Opin Microbiol doi:https://doi.org/10.1016/j. mib.2012.09.006

Peraza L, Hansberg W (2002) Neurospora crassa catalases, singlet oxygen and cell differentiation Biol Chem 383:569-575 doi:Doi https:// doi.org/10.1515/Bc.2002.058

Perkins DD, Davis RH (2000) Neurospora at the millennium. Fungal Genet Biol 31:153-167. https://doi.org/10.1006/fgbi.2000.1248

Rensing L, Monnerjahn C, Meyer U (1998) Differential stress gene expression during the development of Neurospora crassa and other fungi. FEMS Microbiol Lett 168:159-166

Rerngsamran P, Murphy MB, Doyle SA, Ebbole DJ (2005) Fluffy, the major regulator of conidiation in Neurospora crassa, directly activates a developmentally regulated hydrophobin gene. Mol Microbiol 56:282-297. https://doi.org/10.1111/j.1365-2958.2005. 04544.x

Roberts AN, Berlin V, Hager KM, Yanofsky C (1988) Molecular analysis of a Neurospora crassa gene expressed during conidiation. Mol Cell Biol 8:2411-2418

Roche CM, Loros JJ, McCluskey K, Glass NL (2014) Neurospora Crassa : looking back and looking forward at a model microbe. Am J Bot 101:2022-2035. https://doi.org/10.3732/ajb.1400377

Ruger-Herreros C, Rodríguez-Romero J, Fernández-Barranco R, Olmedo M, Fischer R, Corrochano LM, Canovas D (2011) Regulation of conidiation by light in aspergillus nidulans Genetics 188 doi: https://doi.org/10.1534/genetics.111.130096

Sargent ML, Kaltenborn SH (1972) Effects of medium composition and carbon dioxide on circadian conidiation in $<\mathrm{em}>$ Neurospora $</ \mathrm{em}>$. Plant Physiol 50:171-175

Shen WC, Wieser J, Adams TH, Ebbole DJ (1998) The Neurospora rca-1 gene complements an Aspergillus flbD sporulation mutant but has no identifiable role in Neurospora sporulation. Genetics 148:10311041

Shomin-Levi H, Yarden O (2017) The Neurospora crassa PP2A regulatory subunits RGB1 and B56 are required for proper growth and development and interact with the NDR kinase COT1. Front Microbiol 8:1694. https://doi.org/10.3389/fmicb.2017.01694

Smith KM et al (2010) Transcription factors in light and circadian clock signaling networks revealed by genomewide mapping of direct targets for Neurospora white collar complex. Eukaryot Cell 9:15491556. https://doi.org/10.1128/EC.00154-10

Springer ML (1993) Genetic control of fungal differentiation: the three sporulation pathways of Neurospora crassa. BioEssays 15:365-374. https://doi.org/10.1002/bies.950150602

Springer ML, Yanofsky C (1989) A morphological and genetic analysis of conidiophore development in Neurospora crassa. Genes Dev 3: $559-571$ 
Springer ML, Yanofsky C (1992) Expression of con genes along the three sporulation pathways of Neurospora crassa. Genes Dev 6:10521057

Springer ML, Hager KM, Garrett-Engele C, Yanofsky C (1992) Timing of synthesis and cellular localization of two conidiation-specific proteins of Neurospora crassa. Dev Biol 152:255-262

Sun X, Zhang H, Zhang Z, Wang Y, Li S (2011) Involvement of a helixloop-helix transcription factor $\mathrm{CHC}-1$ in $\mathrm{CO}(2)$-mediated conidiation suppression in Neurospora crassa. Fungal Genet Biol 48:1077-1086. https://doi.org/10.1016/j.fgb.2011.09.003

Sun X et al (2012) Analysis of the role of transcription factor VAD-5 in conidiation of Neurospora crassa. Fungal Genet Biol 49:379-387. https://doi.org/10.1016/j.fgb.2012.03.003

Taylor JW, Berbee ML (2006) Dating divergences in the Fungal Tree of Life: review and new analyses. Mycologia 98:838-849

Taylor JW, Ellison CE (2010) Mushrooms: morphological complexity in the fungi. Proc Natl Acad Sci U S A 107:11655-11656. https://doi. org/10.1073/pnas.1006430107

Turner GE, Borkovich KA (1993) Identification of a G protein alpha subunit from Neurospora crassa that is a member of the Gi family. J Biol Chem 268:14805-14811

Turner BC, Perkins DD, Fairfield A (2001) Neurospora from natural populations: a global study. Fungal Genet Biol 32:67-92. https:// doi.org/10.1006/fgbi.2001.1247

Won S, Michkov AV, Krystofova S, Garud AV, Borkovich KA (2012) Genetic and physical interactions between $\mathrm{G} \alpha$ subunits and components of the $G \beta \gamma$ dimer of heterotrimeric $G$ proteins in Neurospora crassa. Eukaryot Cell 11:1239-1248. https://doi.org/10.1128/EC. 00151-12

Wright SJ, Inchausti R, Eaton CJ, Krystofova S, Borkovich KA (2011) RIC8 is a guanine-nucleotide exchange factor for Galpha subunits that regulates growth and development in Neurospora crassa. Genetics 189:165-176. https://doi.org/10.1534/genetics.111. 129270

Xiang Q, Glass NL (2002) Identification of vib-1, a locus involved in vegetative incompatibility mediated by het-c in Neurospora crassa. Genetics 162:89-101

Yang Q, Poole SI, Borkovich KA (2002) A G-protein beta subunit required for sexual and vegetative development and maintenance of normal $\mathrm{G}$ alpha protein levels in Neurospora crassa. Eukaryot Cell 1: 378-390. https://doi.org/10.1128/EC.1.3.378

Ziv C, Feldman D, Aharoni-Kats L, Chen S, Liu Y, Yarden O (2013) The N-terminal region of the Neurospora NDR kinase COT1 regulates morphology via its interactions with MOB2A/B. Mol Microbiol 90: 383-399. https://doi.org/10.1111/mmi.12371

Publisher's note Springer Nature remains neutral with regard to jurisdictional claims in published maps and institutional affiliations. 